\title{
TIEMPOS RECIOS, TIEMPOS DE GRACIA: LA IGLESIA ANTE LA PANDEMIA
}

RESUMEN: El presente artículo expone los desafíos que plantea a la Iglesia la pandemia que está asolando a la humanidad. El foco se pone en las acciones y actitudes pastorales necesarias para aquellos que desempeñan el ministerio sacerdotal, en ámbitos como el acompañamiento del duelo de quienes que han perdido seres queridos, los procesos de reforma de vida ante el impacto de la enfermedad y la alteración de la vida que produce, las necesidades sociocaritativas, celebrativas, educativas o de defensa de la vida, así como los cultivos espirituales para responder evangélicamente a la situación que atravesamos. La experiencia humana de la que se parte es, pues, el fenómeno totalizante de la COVID-19 y el marco doctrinal lo da el magisterio del papa Francisco, sobre todo su última encíclica Fratelli tutti. Sobre la fraternidad y la amistad social (2020), publicada varios meses tras el estallido de la pandemia, y también Evangelii gaudium (2013). El magisterio del Cardenal Arzobispo de Madrid también tendrá su lugar significativo.

PALABRAS CLAVE: pandemia; presbíteros; crisis; discernimiento; Fratelli tutti; conversión pastoral; conversión misionera.

\section{Hard Times, Times of Grace: The Church in the Face of the Pandemic}

ABSTRACT: This article presents the challenges that the current pandemic, which is ravaging Humankind, poses to the Church. The focus is on the pastoral actions and attitudes necessary for those who carry out the priestly ministry, in areas

Universidad Pontificia Comillas: juliomm@comillas.edu;

ORCID: https://orcid.org/0000-0003-3108-4502 
such as accompaniment of the mourning of those who have lost loved ones, the processes of renewal and reform of life in the face of the impact of the disease, and the alteration of life that it produces, the socio-charitable, celebrative, educational, familiar, and defense needs of life, as well as the spiritual cultivation and foundations to respond evangelically to the harsh situation that we are enduring. The human experience from which it emanates stems from the all-encompassing phenomenon of COVID-19, and the Doctrinal framework is found in the Magisterium of Pope Francis, especially his latest Encyclical Fratelli tutti: On Fraternity and Social Friendship (2020), published several months after the outbreak of the pandemic, and also in Evangelii gaudium (2013). The Magisterium of the Cardinal Archbishop of Madrid will also have a significant place.

KEY WORDS: pandemic; priests; parishes; crisis; discernment; Fratelli tutti; pastoral conversion; missionary conversion.

\section{INTRODUCCIÓN}

A petición del Cardenal Osoro el 12 de noviembre de 2020 compartí con los miembros del Consejo Presbiteral ampliado de la archidiócesis de Madrid unas reflexiones sobre cómo nos afecta el gran golpe de la pandemia en nuestro ministerio pastoral de presbíteros. Les puse por título Tiempos recios, tiempos de gracia. Acepté el encargo del arzobispo obedientemente, con humildad y con conciencia de estar ante algo que me desborda, sin intención de enseñar nada y con deseos sinceros de ayudar a pensar juntos en materias que son nucleares para la vida de la Iglesia y, por tanto, también para la vida de los presbíteros, tanto de los diocesanos como de los religiosos.

Para mi reflexión tuve presentes los trabajos elaborados ${ }^{1}$ antes del verano que el Cardenal pidió sobre la situación pandémica a varios grupos de personas ${ }^{2}$, entre los cuales me encuentro ${ }^{3}$, y también su carta Quiero

1 Archidiócesis de Madrid. Un plan para resucitar. Grupos de trabajo y reflexiones sobre la Iglesia en la pandemia. Madrid, 2020. Ad usum privatum.

2 Se crearon cinco grupos de trabajo, a saber: 1) servicios sociocaritativos, 2) reflexión de fondo, 3) comunicación con la sociedad, 4) política y 5) cultura.

3 Se me encargó coordinar un grupo de pensamiento sobre lo que se espera de la Iglesia ante la pandemia. Elaboramos un documento titulado: Comunión, cuidado y reconstrucción: La contribución de la Iglesia de Madrid. El grupo de reflexión estuvo formado, en orden alfabético, por Irene Arrimadas (Escuelas Católicas), José Carlos Bermejo (Fund. Humanizar), Juan Carlos Carvajal (U. San Dámaso), Guillermo Fernández Mállo (FOESSA-Cáritas), Pedro José Gómez (UCM), Teresa López (UCM), 
entrar en tu casa del 22 de agosto de 2020, así como el magisterio del papa Francisco, sobre todo la exhortación Evangelii gaudium (EG, 2013) y la encíclica Fratelli tutti (FT, 2020), así como sus meditaciones en torno a la pandemia, sin desdeñar nada de lo que me pudiese ayudar en la tarea.

\section{CLAVES DADAS POR EL PAPA FRANCISCO ANTE LA PANDEMIA}

Estamos viviendo una situación singular como humanidad; una situación excepcional causada por un fenómeno totalizante, que ha movilizado todas las estructuras, contradicciones y potencias de este mundo: todo se ha visto afectado y reorientado por esta enfermedad mundial; todos nos sentimos amenazados porque a cualquiera le puede tocar y a muchos les toca, causándoles un daño atroz.

La pandemia ha acelerado e intensificado las tendencias que, en mayor o menor medida, ya estaban en marcha. Ha afectado desde las experiencias más íntimas y familiares, hasta las relaciones internacionales. También está afectando, cómo no, a nuestro modo de ser Iglesia. Es ampliamente compartido que la pandemia, por su carácter disruptivo, está provocando un cambio de época cuyas características y nuevos desafíos están por discernir.

Claro que en las circunstancias que vivimos, estamos viendo cómo se origina mucho daño en forma de conductas irresponsables, de acción política que polariza la sociedad y aprovecha la desoladora coyuntura para sacar adelante cambios cargados de ideologización, validando la expresión de la sabiduría popular que sentencia: «a río revuelto ganancia de pescadores». Pero también ha habido muchos hechos que han puesto de manifiesto la grandeza humana y mucho bien brotando del corazón de las personas y de la vida de las instituciones que nos animan y muestran cuáles son las fortalezas sobre las que poder apoyarnos y los caminos que queremos recorrer.

Cuando el estallido de la pandemia se hizo patente, el papa Francisco pidió al Dicasterio para el Desarrollo Humano Integral que se dedicara

Pablo Martínez Anguita (URJC), Federico Montalvo (Comillas, Comité de Bioética de España), Sebastián Mora (Comillas), Elena Postigo (UFV), María Solano (CEU) y Fernando Vidal (Comillas), bajo la coordinación de Julio L. Martínez, SJ (de este texto asumo aquí algunos contenidos). 
a pensar y diseñar acciones concretas y operativas para dar respuesta a las necesidades de hoy y de mañana. La petición del papa Francisco marcaba las siguientes pautas:

- Esta crisis ha disparado lo que ya se venía anunciando: estamos ante un cambio epocal. Habrá un antes y un después de la COVID-19. Constituye un kairós que no se puede desaprovechar como Iglesia y que exige oración y discernimiento.

- Justicia, caridad y solidaridad son las virtudes que mejor muestran con eficacia el rostro misericordioso de Dios y que deben guiar las prioridades de la Iglesia.

- Todos somos mendigos de sentido; debemos ir a lo esencial y trascender lo puramente instrumental para volver a nuestro ser Iglesia, cimentada en el Señor Jesús, la «Piedra angular», alentada por su Espíritu que invita a vivir la santidad de los hijos de Dios en medio del mundo y del sufrimiento.

- La realidad viene reclamando «otro modo» de hacer las cosas. Sin duda, habrá que acompañar a los familiares de los difuntos, multiplicar los funerales o prodigarse en repartir alimentos y ayudas de emergencia, pero nos equivocaríamos si sólo hiciésemos eso. El momento presente reclama un nuevo modo de afrontar la misión. (En cuatro palabras lo ha sintetizado el Cardenal Osoro en su carta Quiero entrar en tu casa: comunión, sinodalidad, unidad y tensión evangelizadora).

\section{UN ESTRUENDOSO ALDABONAZO PARA DESPERTAR}

En su meditación titulada Un plan para resucitar publicada en la revista Vida Nueva el 17 de abril de 2020, Francisco señala que como pocas veces en la historia, la humanidad ha cobrado aceleradamente conciencia de su enorme finitud y, al mismo tiempo, de su interdependencia y de la necesidad de ayudarnos los unos a los otros: hemos aprendido que nadie se salva solo y que nuestra suerte está unida a la de nuestro vecino y viceversa.

- Los «anticuerpos de la solidaridad» romperán todo el fatalismo en el que estamos inmersos y permitirá volver a sentirnos artífices y protagonistas de una historia común y, así, responder mancomu- 
nadamente a tantos males que aquejan a millones de hermanos alrededor del mundo.

- No podemos permitirnos escribir la historia presente y futura de espaldas al sufrimiento de tantos. Es el Señor quien nos volverá a preguntar «¿dónde está tu hermano?» $(\mathrm{Gn} 4,9)$ y, en nuestra capacidad de respuesta, ojalá se revele el alma de nuestros pueblos, ese reservorio de esperanza, fe y caridad en la que fuimos engendrados y que por tanto tiempo hemos anestesiado o silenciado.

- No tengamos miedo a vivir la alternativa de la civilización del amor, que es «una civilización de la esperanza: contra la angustia y el miedo, la tristeza y el desaliento, la pasividad y el cansancio. La civilización del amor se construye cotidianamente, ininterrumpidamente. Supone el esfuerzo comprometido de todos. Supone, por eso, una comprometida comunidad de hermanos».

- Urge discernir y encontrar el pulso del Espíritu para impulsar junto a otros las dinámicas que puedan testimoniar y canalizar la vida nueva que el Señor quiere generar en este momento concreto de la historia.

- Este es el tiempo favorable del Señor, que nos pide no conformarnos ni contentarnos y menos justificarnos con lógicas sustitutivas o paliativas que impiden asumir el impacto y las graves consecuencias de lo que estamos viviendo.

La encíclica Fratelli tutti ha venido a hacer una impresionante síntesis del aldabonazo que recibe la humanidad con esta gran crisis al recordarnos la común pertenencia humana que nos hace hermanos e hijos de Dios y cómo la obscurecemos. El 30 de marzo lo anticipó el papa en la bendición al mundo con la Cruz en la plaza de San Pedro: «Nos dimos cuenta de que estábamos en la misma barca, todos frágiles y desorientados; pero, al mismo tiempo, importantes y necesarios, todos llamados a remar juntos, todos necesitados de confortarnos mutuamente. En esta barca estamos todos [...] No podemos seguir cada uno por nuestra cuenta, sino sólo juntos [...] Comprendemos que nadie se salva solo. Frente al sufrimiento, donde se mide el verdadero desarrollo de nuestros pueblos, descubrimos y experimentamos la oración sacerdotal de Jesús: "Que todos sean uno" (Jn 17,21)».

La reacción contra la pandemia ha mostrado "cómo nuestras vidas están tejidas y sostenidas por personas comunes que, sin lugar a duda, 
escribieron los acontecimientos decisivos de nuestra historia compartida» (FT, 54).

Hemos podido ver la grandeza del servicio y la entrega, incluso de la propia vida, en tantos profesionales esenciales, entre ellos a sacerdotes y religiosos que han estado dando asistencia espiritual a tantos enfermos y familias en duelo en las peores circunstancias.

\section{PASTORES HERIDOS Y COMPASIVOS CON LAS HERIDAS DE MUCHOS}

Eso sí, nos duele que muchos pacientes hayan sido privados del acompañamiento y la asistencia espiritual durante sus procesos de morir, aplicando una regla general y taxativa a todos los casos y obviando una mínima reflexión acerca de las posibilidades de haber facilitado acompañamiento o asistencia espiritual, por considerarlos como secundarios o incluso prescindibles. Ahora nos encontramos en una situación postraumática que padecen en distintos modos y grados quienes han enfermado, han cuidado, han sufrido pérdidas de seres queridos o están sufriendo la destrucción de empleo y empresas; y también la padece la inmensa mayor parte de la población en quien ha impactado este drama. La imposibilidad de despedirse de un ser querido, de un padre, una madre, un amigo, está dejando secuelas en un número muy elevado de personas, que seguro necesitarán apoyo para superarlas. Las familias que tenían a sus mayores en residencias y han fallecido, han sufrido experiencias internas muy complejas. Nos encontramos con personas que se han visto superadas por el miedo o la incertidumbre al no poder o saber acompañar a sus seres queridos y eso les puede causar remordimientos, que hay que poner bajo la mirada del perdón.

Estos sentimientos doloridos aún nos llevan a querer comprometernos más con ser pastores buenos con aquellos que tienen el corazón herido. Pedimos humildemente al Señor el don de acompañar los procesos de duelo y de ayudar a sanar heridas desde el reconocimiento de las semillas de bien que Dios sigue derramando en la humanidad.

En esa atención al duelo debemos escuchar y necesitamos encontrar la palabra que consuela y sana, y los signos y ritos que humanizan el final de la vida y la llevan a la esperanza. Los ritos hacen habitable el tiempo, lo ordenan y ayudan a que los eventos tengan sentido, como pone de manifiesto 
el filósofo Byung-Chul Han en su última obra, La desaparición de los rituales (2020); a través de ellos experimentamos corporalmente la comunidad.

\section{UNA LLAMADA A REFORMAR DE VIDA}

La Iglesia guiada por el Espíritu del Señor resucitado es para el mundo fuente surtidora de sentido necesario para elaborar la experiencia personal y reconstruir el tejido comunitario. Una de las labores fundamentales que debe realizar la Iglesia en sus diversos ámbitos, ya sean comunitarios, personales o especializados, es la de custodiar y ayudar a sanar la memoria de lo vivido, esas experiencias de periferia extrema donde lo humano se ha revelado en su debilidad, pero también en su grandeza en toda su densidad. Aunque muchas veces consideramos que el silencio y el aislamiento es la cura para el dolor y pensamos que sólo tomando medidas efectivas salimos de las situaciones dramáticas; en realidad se hace necesario dar espacio y palabra a lo vivido. Es necesario crear múltiples oportunidades para profundizar y reformar la propia vida. Si la economía necesita reconstruir medios de producción, la sociedad precisa disponer de medios de reflexión.

Tenemos aquí un campo en el que hacer una gran aportación práctica, poniendo nuestra experiencia en facilitar procesos de cambio personal y reforma de vida. Los auténticos cambios son efectivos y duraderos sólo si están fundados sobre actitudes internas y personalizadas, que no se puede esperar que los demás adopten por uno mismo, ni delegar a las instituciones. En su conjunto, hay una llamada a un estilo de vida más sencillo, solidario y profundo. «El dolor, la incertidumbre, el temor y la conciencia de los propios límites que despertó la pandemia, hacen resonar el llamado a repensar nuestros estilos de vida, nuestras relaciones, la organización de nuestras sociedades y sobre todo el sentido de nuestra existencia» (FT, 33).

Necesidades de orientación personal hay muchas; el gran reto está en si logramos abrir lenguajes y perspectivas para que no quedar limitados a quienes se mueven con facilidad y costumbre a los códigos y espacios intraeclesiales. El reto está en inculturarse en los lugares y lógicas de la gente para saber acompañar en sus caminos. Y me atrevo a decir que los medios de reflexión que ofrecemos hoy necesitan una reconversión. 
Diálogo y encuentro, para la Iglesia, son su modo de ser y estar en el mundo. La Iglesia es «lugar de la misericordia gratuita» (EG, 114), donde se «cura el desencanto, la desesperanza, la desilusión, se acompaña a las personas concretas en sus necesidades concretas; donde se cura la desorientación, para que todos descubramos que nuestra trayectoria vital no es la de un vagabundo, que no sabe dónde ir, sino la de un peregrino, que tiene una meta a la que llegar» ${ }^{4}$.

\section{NUEVAS FORMAS DE VIVENCIA Y EXPRESIÓN DE LA FE}

La actividad sacramental y espiritual de la gente ha quedado drásticamente afectada por las normas de confinamiento y ahora sigue afectada en esta nueva fase de la pandemia, con el riesgo evidente de que mucha gente que antes iba físicamente no vuelva a las celebraciones. Unos no volverán porque han fallecido y otros porque han cogido miedo o pereza. Es verdad que eso puede suceder, pero no dejemos hoy por ello de alegrarnos por tantas acciones creativas que se han producido a través del teléfono que ha sido una gran herramienta para la escucha y el acompañamiento espiritual o las videoconferencias que han mantenido viva la llama de los diversos grupos de fe, de matrimonios, de revisión de vida o de formación. Miles de iniciativas de celebración a distancia de plegaria, meditación o reflexión, promovidas desde parroquias, escuelas, universidades, comunidades laicales, redes digitales y los más variados espacios. Las redes se han convertido en un gran instrumento para la celebración y transmisión de la fe. Son canales diferentes de los habituales, con altas dosis de ambivalencia, pero en ellos no podemos dejar de estar e ir juntos aprendiendo a transmitir la buena noticia del Evangelio, a crear verdadera cultura del encuentro a través de los canales con los que hoy cuenta la mayor parte de la gente.

Todo eso sin perder de vista los riesgos que Francisco señala en FT. Por ejemplo, advierte sobre una comunicación virtual que hace creer que una pantalla basta para estar integrados, o sobre la necesidad de consumir sin límites junto con la acentuación de muchas formas de individualismo sin contenidos, o sobre las grandes palabras (unidad, fraternidad, libertad,

${ }^{4}$ Manuel Bru. “¿Qué significa la Cultura del Encuentro?”. Aleteia (26 de noviembre de 2014) (acceso web 18/8/2016). 
democracia) que se vacían de sentido o se manipulan a partir de nuevas formas de colonización cultural, una cultura mediática y virtual que tiende a exasperar, exacerbar y polarizar (FT, 15), cuando no cae en «movimientos digitales de odio y destrucción» (FT, 43), donde además todo «puede ser espiado, vigilado, y la vida se expone a un control constante». Así «el respeto al otro se hace pedazos» (FT, 42) y la cultura del encuentro se vuelve una mera utopía. Hemos de estar alerta de tanta ambivalencia, pero sin dejar de utilizar la digitalización para el bien, porque ese bien no es simple ensoñación, sino que lo hemos palpado.

Me permito hacer con vosotros la siguiente reflexión: tenemos el peligro de ver la parte negativa con las cosas que no estamos suficientemente familiarizados y que de algún modo nos descolocan. Creo que debemos hacer el esfuerzo por valorar lo positivo de las nuevas tecnologías y cómo pueden ayudar a poner a la persona en el centro. La pandemia, en ese sentido, está siendo un potente acelerador de procesos. Por ejemplo, en la Universidad nos ha permitido dar un salto de años en innovación educativa y navegar con solvencia a través de las turbulencias de estos meses.

No está de más tener en cuenta que la sostenibilidad de la sociedad pasará necesariamente por la digitalización; ambas van de la mano. No vendría mal que se tuviese en cuenta la organización de cursos aplicados a las necesidades de las parroquias e introducir de una forma eficaz tanto las habilidades tecnológico-comunicativas, como la reflexión seria sobre su ambivalencia en la formación de los nuevos sacerdotes. Me consta la preocupación que sobre estos temas tiene el actual rector del Seminario de Madrid.

\section{LOS JÓVENES Y EL CULTIVO DE LA INTERIORIDAD}

Me resultan interesantes igualmente unas palabras de don Carlos sobre los jóvenes en su última carta pastoral para este curso 2020-21 perfilando «el sueño misionero de llegar a todos» del que siempre nos habla siguiendo la senda de EG: «Quizás los jóvenes nos están ayudando en el sentido de ir a lo esencial [...]. Ellos son libres para encontrar caminos nuevos con creatividad y audacia. Si estamos atentos a la vida de los jóvenes, a sus intereses y necesidades, ellos mismos nos indicarán que es necesario asumir nuevos estilos y nuevas estrategias. Nosotros, los mayores, todo lo tenemos previsto y programado; ellos asumen la flexibilidad, se forman, pero de 
otra manera, comparten la vida, celebran, cantan, escuchan, ofrecen y relatan testimonios reales y viven con emoción la experiencia del encuentro comunitario con el Dios vivo» (Osoro, Quiero entrar en tu casa, 68).

Necesitamos una pastoral y una educación que abra y confronte a las personas con la realidad, y que las ponga en contacto con su propia interioridad, no para mirarse el ombligo, autorreferencialmente, sino para entren en procesos formativos que les vayan haciendo progresivamente llegar a ser personas conscientes, competentes, críticas, compasivas y comprometidas. "Conscientes de sí mismas y del mundo en que viven, con sus dramas, pero también con sus gozos y esperanzas. Competentes para afrontar los problemas técnicos, sociales y humanos [...]. Personas también movidas por una fuerte compasión ${ }^{5}$. Esta compasión es el motor a largo término que mueve al compromiso: esta forma de amar en la que el ser humano no sólo da algo, sino que se da a sí mismo a lo largo del tiempo» ${ }^{6}$.

Tengo la convicción de que si no acertamos con las claves para posibilitar el cultivo de la interioridad será vano cualquier empeño de formación integral, por muy expertos que sean y muchas ganas que tengan los educadores o los evangelizadores.

\section{EL FUNDAMENTAL ROL DE LA FAMILIA}

Hablando ahora de la familia, creo que se puede aplicar también la cuestión de la interioridad. El consumismo, el exceso de tiempo individual frente a pantallas, la pérdida de la dimensión celebrativa y de hábitos saludables, la pasivización y la no transmisión de la sabiduría de humanidad, debilitan la «interioridad» de la familia y a cada uno de sus miembros. Frente a ello necesitamos familias activas, narrativas y serviciales, y propuestas que nos lleven a ello.

Las relaciones intrafamiliares se han visto fuertemente sacudidas por la crisis sanitaria que ha obligado a un confinamiento muy largo, situación que en muchos casos ha sido una magnífica oportunidad para disfrutar de los hijos y de los padres, pero en otros muchos se han acrecentado las tensiones que existían pero que la falta de tiempo en común había tapado.

\footnotetext{
${ }^{5}$ Compasión en el sentido de empatía que hace posible ponerse en el lugar del otro.

6 Adolfo Nicolás. Misión y Universidad ¿Qué futuro queremos? Barcelona: ESADE, 2008.
} 
Ha habido familias que han redescubierto valores y el gusto por vivir juntos, pero otras familias han entrado en crisis porque se han tensado más las contradicciones o malestares. Muchas familias, muy especialmente aquellas que tienen condiciones de vida precarias y situaciones económicas vulnerables, han sufrido una enorme presión por el confinamiento, la falta de espacio doméstico, la pérdida de empleo y las incertidumbres.

Debemos impulsar la pastoral de las familias. Las familias son el primer ámbito de memoria y de las relaciones gratuitas. La escucha, la acogida, la atención, el acompañamiento mutuo las convierte en el entorno humano privilegiado en donde las energías se concentran para que sus miembros puedan afrontar los retos concretos a los que se tienen que enfrentar. Y, sin embargo, hoy sufre una gran erosión. La Iglesia debe pasar de la retórica respecto a la realidad familiar y propiciar una mayor atención, especialmente a las más vulnerables, superando "doctrinas sin vida»: familias monoparentales, de emigrantes, amenazadas por el paro... La atención a los núcleos familiares es el mejor modo de superar la tentación del «sálvese quien pueda».

\section{LA DIMENSIÓN SOCIOEDUCATIVA}

Si por ahí van las urgencias educativas son lamentables todos los obstáculos y trabas que se quieren imponer a la acción de las instituciones católicas concertadas. No es el momento de poner trabas, de enfrentar instituciones públicas y privadas, sino de trabajar conjuntamente, de cooperar de forma eficaz y eficiente para ofrecer una educación adecuada a todos los niños, adolescentes y jóvenes de nuestro país, respetando en todo momento el derecho constitucional de los padres y madres a escoger libremente el centro y el modelo educativo para sus hijos —en consonancia a su conciencia, identidad y tradiciones-, y asegurando siempre el derecho constitucional a la libre iniciativa privada.

Quiero creer que la inmensa mayoría de la sociedad está a favor de un pacto educativo en España que sea a largo plazo y que incorpore a todas las fuerzas políticas y también a las entidades civiles y religiosas activas en el campo de la educación. Sería conveniente que este pacto educativo pudiera concretarse en una ley sólida que no sea objeto de debate con cada 
cambio de color político en el Gobierno. Desgraciadamente, no vamos a tener ni pacto ni ley integradora.

Cuando el papa le dijo hace unos días al presidente del Gobierno que es necesario «construir la patria con todos [...] donde no nos es permitido el borrón y cuenta nueva» seguramente una de las cuestiones que tenía en mente es el pacto educativo.

\section{DESVIVIRSE POR CREAR CAUCES DE «ENCUENTRO»}

No es momento de divisiones, no es momento para dejar que los brotes populistas irresponsables e ideológicos traten de colarse. Es el momento de la cohesión, de la concordia, de trabajar unidos, de mirar a largo plazo liberándonos del cortoplacismo de las elecciones o de la bolsa. Como también le dijo el papa, «las ideologías sectarizan, las ideologías deconstruyen la patria, no construyen», es necesario «aprender de la historia» y respetar la memoria.

La situación de multicrisis que vivimos está sometiendo a nuestras sociedades a un intenso estrés que agudiza la división entre unos y otros. Ante el riesgo de que las crisis hagan aflorar el resentimiento, la polarización y la división, debemos potenciar la comunión para vencer este desafío que no es sólo sanitario, sino también económico, social, político y espiritual.

La tarea de reducir la crispación y de promover la cultura del encuentro no sólo corresponde a los medios de comunicación y a las figuras políticas y públicas, sino también a cada uno de nosotros. Lo podemos hacer en nuestros contextos diarios, en las conversaciones, en las redes sociales, en la formación de los niños y jóvenes, en los mensajes que ponemos en circulación en la sociedad. No debemos dar al mal más alas, sino que debemos dar continuamente oportunidades a la concordia y a la reconciliación, tal como nos aconseja el papa cuando afirma que «cada uno de nosotros está llamado a ser un artesano de la paz, uniendo y no dividiendo, extinguiendo el odio y no conservándolo, abriendo las sendas del diálogo y no levantando nuevos muros» (FT, 284). 


\section{LA DIMENSIÓN SOCIOCARITATIVA}

Hay otra dimensión fundamental en la que muchos de los presentes estáis implicados y en la que vais a tener que perseverar ante la situación dramática de muchas personas: la sociocaritativa. La pandemia ha agudizado una crisis que reclama de nosotros, del conjunto de la sociedad y de las administraciones públicas un esfuerzo sin precedentes, tanto en respuestas «estructurales como en creatividad, presencia y cercanía al dolor de nuestra gente» (C. Osoro, Quiero entrar en tu casa, 36). Junto con muchas iniciativas vecinales, desde parroquias y centenares de redes del bien, hemos repartido miles de toneladas de alimentos. Hemos ayudado a muchas personas en situaciones de dependencia, soledad y angustia; e intentado resolver los más diversos problemas de la gente. La Iglesia ha multiplicado exponencialmente su atención a las personas y a las familias vulnerables a través de Cáritas y de la numerosa red de entidades impulsadas por todo tipo de instituciones y comunidades cristianas. Todo esto está teniendo una cierta visibilidad en los medios de comunicación, quizás mucho menos de lo que en realidad se está haciendo, pero lo más valioso es responder activamente aun cuando no se nos dé mucha resonancia.

El cierre de los templos y las restricciones de aforo han provocado que las colectas hayan menguado. A no pocas parroquias ya les está costando llegar a fin de mes y las diócesis están saliendo al paso con planes de emergencia para garantizar que puedan seguir con su labor pastoral y asistencial. Toca ser creativos para implicar a los fieles en esta misión de servicio a los necesitados, tanto en la obtención de recursos económicos como en el de manos para ayudar.

Con todo, es muy importante la llamada que se nos hace explícita a vivir «la proximidad y la amistad con los pobres», con los que más necesitan; una «invitación a mirar y admirar, a reconocer el misterio sagrado que tienen y esconden las personas empobrecidas, así como a no dejar de ver el porqué de esta pobreza» (C. Osoro, Quiero entrar en tu casa, 36). Aquí se adelanta el Cardenal Osoro al papa, que también pide en FT «amistad con los pobres» (FT 234), esa es la prueba de que nuestro amor es realmente universal, en medio de este mundo fragmentado que descarta a tantos. 


\section{RECONSTRUCCIÓN DEL SENTIDO DE VECINDAD}

El redescubrimiento de los vecinos ha sido una de las experiencias más universales durante la pandemia, especialmente en las ciudades, donde la sociabilidad vecinal se ha ido progresivamente desgastando. Según estudios de la cátedra Amoris Laetitia, que dirige el profesor Fernando Vidal, el 37,3\% de los habitantes de Madrid carece de vecinos a quienes pedir un favor importante. Un tercio de la población carece de vecinos con los que tenga una relación de solidaridad y ese porcentaje se eleva desproporcionadamente cuando se trata de jóvenes, gente sin hijos, desempleados, estratos económicamente vulnerables e inmigrantes. La gran desvinculación que hemos sufrido ha ido destejiendo los lazos vecinales que tan importantes fueron para las anteriores generaciones y que tan importantes son en los barrios más dinámicos, sostenibles y con mayores grados de satisfacción entre sus habitantes. Podremos avanzar desde esta experiencia y recuperar el hecho de tener vecinos y barrios, o podemos regresar a lo de antes, a un mundo sin vecinos. ¿Podremos hacer algo desde las parroquias, como casa, mesa y plaza de todos y para todos para contribuir a la vinculación y solidaridad vecinal?

Desde luego, la Iglesia, con su extensa red parroquial, tiene capacidad para ayudar a crear el nuevo vecinalismo, si es suficientemente creativa, abierta e inclusiva; y de tal capacidad se deriva una responsabilidad importante. El problema de las parroquias es, en parte, de desvinculación comunitaria más general. Revincular el barrio ayuda a revincular la parroquia.

El presbítero, ministro de la comunión, tiene un papel esencial en esa reintegración y participación, para cuidar el «caminar juntos» en cada espacio. La parroquia es para los cristianos y su expresión catequética y celebrativa, sin embargo, sólo la dimensión caritativa ha permanecido abierta para ayudar a todo tipo de personas. Esta realidad ha empobrecido el tejido relacional de la Iglesia y su presencia en el espacio social. Ha perdido puentes para el «diálogo con el mundo». ¿Serán posibles planes que recreen las parroquias como espacios de encuentro con los barrios? ¿Podremos hacer algo más en el sentido de abrir nuestros locales, salir a las plataformas vecinales o participar en espacios de coordinación pública, generando espacios culturales alternativos? 


\section{LA MIRADA UNIVERSAL ARRAIGADA EN EL COMPROMISO CON LO LOCAL}

Incluso en momentos en que la situación de nuestra sociedad requiere tanta atención, sólo si tenemos una mirada universal y cosmopolita seremos capaces de encontrar las soluciones. Especialmente debemos tener presente la situación de las personas y lugares más vulnerables del mundo y reforzar nuestra solidaridad con ellos, evitando la posible invisibilidad que pudieran alcanzar en este momento.

La encíclica Fratelli tutti señala con especial insistencia el riesgo que amenaza a las personas migrantes y que parece haber cuajado en ideologías xenófobas que ceden a "la tentación de hacer una cultura de muros» (FT, 27). «Es verdad que lo ideal sería evitar las migraciones innecesarias y para ello el camino es crear en los países de origen la posibilidad efectiva de vivir y de crecer con dignidad, de manera que se puedan encontrar allí mismo las condiciones para el propio desarrollo integral. Pero mientras no haya serios avances en esta línea, nos corresponde respetar el derecho de todo ser humano de encontrar un lugar donde pueda no solamente satisfacer sus necesidades básicas y las de su familia, sino también realizarse integralmente como persona. Nuestros esfuerzos ante las personas migrantes que llegan pueden resumirse en cuatro verbos: acoger, proteger, promover e integrar» (FT, 129). Muchos inmigrantes forman parte de nuestras comunidades parroquiales. Nos necesitan y los necesitamos.

\section{LA PANDEMIA, GOLPE MUY DOLOROSO SOBRE LA VIDA}

Casi todos hemos sentido la fragilidad de una vida humana que necesita ser especialmente cuidada y la consternación por cómo la pandemia y su gestión ha impactado en los límites de la vida. Hemos percibido con claridad con qué facilidad se le resta valor y cómo se somete bajo criterios técnicos que acaban desdibujando el humanismo y compasión que debe preservarse en todo momento.

No sé si a alguno le habrá pasado igual, pero yo ingenuamente creí que la situación postraumática de quienes en distintos modos y grados han enfermado, cuidado o sufrido pérdidas de seres queridos, o no han podido acompañarlos y despedirlos decentemente, iba a hacer repugnante que se replantease el impulso al ordenamiento jurídico para legitimar el 
suicidio asistido y la eutanasia. Pero me he equivocado y aquí tenemos cada vez más cerca una ley que erosionará gravemente la conciencia de lo que hace que la vida humana sea preciosa y resquebrajará aún más los deberes inderogables de la solidaridad y fraternidad humanas. Sé que la conciencia de la gravedad de esto es menos compartida por el conjunto de los ciudadanos, en parte porque durante años se ha ido creando una opinión pública favorable a favor del derecho de elegir una muerte definida impropiamente como digna por haber sido elegida, como diagnosticó san Juan Pablo II en el n. ${ }^{\circ} 72$ de Evangelium vitae.

Mal negocio es golpear el derecho a la vida, fundamento del orden jurídico y de todo otro derecho, incluido el ejercicio de la libertad humana. Desembocar en una cultura que acepta como gran logro que algunos pongan fin a su vida como si fuera indigna o descartable, hiere el corazón de las relaciones humanas, la justicia y la confianza entre las personas; y lanza un mensaje a favor de un individualismo que legitima la decisión subjetiva de los cuidados y la asistencia que cada uno quiera recibir según lo que la autonomía o la utilidad social o económica hagan posible o conveniente. En el contexto pandémico en que han muerto miles de personas, en muchos casos dejadas a su suerte, en lugar de entonar un mea culpa de cómo les hemos fallado y hacer propósitos firmes por defender la vida humana, se atizan las brasas de una legislación para hacer posible elegir la muerte. Surrealista pero cierto. ¿Qué reconstrucción se podrá hacer sobre tal individualismo y subjetivismo moral?

\section{CONVERSIÓN PASTORAL Y MISIONERA}

Hay muchos motivos para estar preocupados, pero ninguno para no escuchar el Evangelio y dejar que esa escucha se transforme en llamada a la conversión y a actuar con confianza y entusiasmo en las nuevas situaciones de la experiencia humana. Necesitamos volver al «amor primero» $($ Ap 2,4), al «manantial que está en la persona de Jesucristo» (Osoro, 17) y desde él, ser una Iglesia valiente y decidida, aun cuando débil y pequeña o accidentada, en una sociedad que mira con reticencias las injerencias que considera externas, pero que necesita desesperadamente fundamentos prepolíticos de solidaridad y de ciudadanía, y necesita una esperanza verdadera. 
Creo que por ahí debe de ir la nueva evangelización: las estrategias o métodos rompedores que podamos utilizar están bien, pero no serán nada sin volver al "amor primero" para hacer posible que los hombres y mujeres que vivimos en esta sociedad tan secularizada y tan crispante volvamos a sentir la alegría de la presencia y de la cercanía del amor de Dios en nuestras vidas. Es volver a sentir la brisa fresca del Evangelio, para dejarse sorprender y maravillar por la palabra de Jesús, como sucedió cuando él inició su vida pública, cuando la gente que lo escuchaba se maravillaba por la autoridad y los gestos que hacía el Señor $(M c 1,27)$.

Parece evidente que para volver al "amor primero" es conditio sine qua non salir de uno mismo, salir del propio amor, querer e interés; e ir a las fronteras existenciales. Ahí está la gran llamada del papa Francisco en nombre de Jesucristo a toda la Iglesia universal, con especial fuerza en Evangelii gaudium siguiendo el impulso del Concilio Vaticano $\mathrm{II}^{7}$, a una «conversión pastoral», a inaugurar «una nueva etapa evangelizadora marcada por la alegría» (EG, 1 y 25), a ser una «Iglesia en salida» (EG, 20) «con las puertas abiertas» (EG, 46), «no preocupada por ser el centro y clausurada en una maraña de obsesiones y procedimientos» (EG, 49), que sale «a las periferias humanas» $(\mathrm{EG}, 46)$.

Esta «conversión misionera» de nuestras Iglesias, parroquias y comunidades cristianas. Ser misioneros es «salir» a las «fronteras» y de las inercias para llevar la alegría del Evangelio a nuestros hermanos. Hace falta pasar de "una pastoral de mera conservación a una pastoral misionera» (EG, 15). «La alegría del Evangelio que llena la vida de la comunidad de los discípulos es una alegría misionera» (EG, 21), para «todos, en todos los lugares, en todas las ocasiones, sin demoras, sin ascos, sin miedos [...], sin exclusiones» (EG, 23). Deseamos aprender a vivir como una Iglesia que sale realmente de sí misma (EG, 20.24), que supera el ensimismamiento para ir al encuentro de los que se fueron o de los que nunca han venido y mostrarles el Dios misericordioso revelado en Jesucristo, que se disponga a ser "hospital de campaña tras una batalla» "curando heridas y dando calor a los corazones» ${ }^{8}$.

7 Cf. Francisco. Misericordiae vultus, n. 4.

8 Entrevista al papa Francisco del P. Antonio Spadaro, SJ. L'Osservatore Romano, edición semanal en lengua española, Año XLV, n. 39 (2.333), viernes 27 de septiembre de 2013. 


\section{SERVIDORES DE LA MISIÓN DE CRISTO}

El Dios que hallamos en todo y al que todo nos lleva es «un solo Dios que es comunión trinitaria», en quien podemos pensar y creer que «toda la realidad contiene en su seno una marca propiamente trinitaria» (LS, 239) y también que la persona humana está llamada a asumir el dinamismo trinitario, saliendo de sí «para vivir en comunión con Dios, con los otros y con todas las criaturas» (LS, 240).

La mirada de la Trinidad — dice Bergoglio- no es la que asciende del tiempo a la eternidad en busca de la visión beatífica definitiva para luego deducir un orden temporal ideal, sino «la que se involucra»; una mirada que le permita al Señor «nuevamente encarnarse» (San Ignacio de Loyola, Ejercicios Espirituales EE, 109) «en el mundo tal como está, para dar vida a todos. Esta mirada universal se vuelve concreta inmediatamente...» (EE, 103). La dinámica es la misma que en el lavatorio de los pies: la conciencia lúcida y omnicomprensiva del Señor (sabiendo que el Padre había puesto todo en sus manos) lo lleva a ceñirse la toalla y lavar los pies a sus discípulos. La visión más alta lleva a la acción más humilde, situada y concreta. El cristianismo no es una «ideología» ni «un simple moralismo - "tienes que hacer" - sino un don en el que se nos ha dado el amor que nos sostiene y nos proporciona la fuerza necesaria para saber "perder la propia vida"; y, por otra, en este contexto de amor donado, [llama a] progresar hacia las realizaciones concretas ${ }^{9}$. Nos pregunta don Carlos si lo que nos mueve es Cristo o unas ideas (Quiero entrar en tu casa, 41, $46,47,69,17)$ y nos invita a volver al manantial, contemplemos a Cristo.

Lo que aprendemos de Jesús en todos sus encuentros y en los momentos cruciales de su vida es a dar valor a las cosas pequeñas en el marco de los grandes horizontes, los del Reino de Dios. «Lo que Jesús nos enseña es primero a encontrarnos, y en el encuentro, ayudar» ${ }^{10}$. El misterio de la Encarnación nos dirige también a la cruz de Cristo, paso necesario de la vida, pero no última palabra.

En el «Jesús roto de la cruz, que no tiene apariencia ni presencia a los ojos del mundo y de las cámaras de TV, resplandece la belleza del amor hermoso de Dios que da su vida por nosotros... Hay hermosura más allá

\footnotetext{
9 Así lo expresó Benedicto XVI en un discurso a los obispos suizos el 9 de noviembre de 2006.

10 Francisco. Mensaje en la Fiesta de san Cayetano-Argentina (7/8/2013).
} 
de la apariencia o de la estética de moda en cada hombre y en cada mujer que viven con amor su vocación personal, en el servicio desinteresado por la comunidad, por la patria; en el trabajo generoso por la felicidad de la familia... comprometidos en el arduo trabajo anónimo y desinteresado de restaurar la amistad social... Hay belleza en la creación, en la infinita ternura y misericordia de Dios, en la ofrenda de la vida en el servicio por amor. Descubrir, mostrar y resaltar esta belleza es poner los cimientos de una cultura de la solidaridad».

Eso sí, es muy importante añadir que la cruz de Jesucristo no sanciona ningún tipo de sacrificio o autoanulación que pacte con la injusticia o la violencia. Por el contrario, la cruz desvela que en el corazón del mundo está la misteriosa presencia de Aquél que se compadece radicalmente de todos los que sufren, y que nos llama a la misericordia compasiva: «El Señor, que nos mira con misericordia y nos elige, nos envía a hacer llegar con toda su eficacia esa misma misericordia a los más pobres, a los pecadores, a los sobrantes y crucificados del mundo actual que sufren la injusticia y la violencia. Sólo si experimentamos esta fuerza sanadora en lo vivo de nuestras propias llagas, como personas y como cuerpo, perderemos el miedo a dejarnos conmover por la inmensidad del sufrimiento de nuestros hermanos y nos lanzaremos a caminar pacientemente con nuestros pueblos aprendiendo de ellos el modo mejor de ayudarlos y servirlos ${ }^{11}$.

\section{EL EVANGELIO SÓLO SE PUEDE DE VERDAD DIFUNDIR CON ACTITUDES EVANGÉLICAS}

«Audaces y creativos» para renovar instituciones y actividades pastorales (EG, 33). Eso sí, tengamos en cuenta que no es posible proponer la Buena Noticia de Jesús de cualquier forma: el Evangelio sólo se difunde desde actitudes evangélicas; los documentos ayudan, pero si van respaldados por la vida y el testimonio de personas, comunidades e instituciones.

Por debajo de la crisis sanitaria que ha disparado otra económico-social, hay una crisis antropológico-cultural de envergadura, de la que no se libra

${ }^{11}$ Discurso del Santo Padre Francisco a los participantes en la 36 Congregación General de la Compañía de Jesús (24/10/2016). Roma: Curia General de la Compañia de Jesús, 2016, n. 2. 
en absoluto la Iglesia. No son tiempos fáciles para nadie, tampoco para la Iglesia y para los que somos ministros ordenados. También a nosotros nos afectan las contradicciones y fatigas. A muchos les puede asaltar la tentación de una «emigración hacia el propio mundo interior» o a un cenáculo de amigos; a no pocos les puede descontrolar haciéndoles perder las referencias, incluso el sentido de pertenencia y los valores fundamentales. Desearíamos, sin embargo, que nos acercase más al amor primero. Así se sentía el P. Arrupe, cuando en momentos difíciles decía: «Tan cerca de nosotros no había estado el Señor, acaso nunca; ya que nunca habíamos estado tan inseguros». Es una forma diferente de decir aquello que dejó consignado san Pablo: «En la debilidad, te basta mi fuerza» (2Cor 12,9).

Desde luego, no significa que la cercanía del Señor cree inseguridad, sino que los pobres, los débiles, los inseguros son los predilectos de Jesús y, por tanto, como enseñan las bienaventuranzas, los más próximos al Reino. Quizás, los que se atreven a vivir en la inseguridad por amor a Cristo. La clave la tenemos en "volver a Jesús» que está vivo y sigue saliendo a nuestro encuentro en el Espíritu como hizo con los dos de Emaús, con María Magdalena, con Tomás o con Zaqueo, como nos muestra estupendamente el Cardenal Osoro en su carta pastoral. Pero bien sabemos cuánto nos cuesta pasar de los documentos y declaraciones a la vida y a una pastoral coordinada, de acentos estratégicos comunes, con planes pastorales ocurrentes, simples y concretos. Pasar de la letra impresa a la vida y poner en riesgo nuestras seguridades.

\section{LA HORA DE LA ESPERANZA CONCRETA}

Tras la pandemia y la crisis desatada, existe un sentimiento de desolación y hay una situación postraumática que produce sentimientos negativos. Quizás se está produciendo un desacople entre el análisis dolido de la situación y las orientaciones al futuro, que todavía no hemos desarrollado. La Iglesia puede ayudar a abrir esos caminos de futuro. Es la hora de la esperanza.

Ante todo, la Iglesia quiere alimentar la esperanza y no una esperanza como sentimiento abstracto, sino una esperanza concreta que reconozca y dé valor a todo lo positivo que emerge en la vida de cada persona, familia y la sociedad en su conjunto. Hay que evitar caer en reacciones destructivas 
y la mera culpabilización colectiva o personalizada, sino sobre todo buscar las enseñanzas éticas que nos pueden ayudar a mejorar. El camino de la vida que el propio Jesús siguió atraviesa todas las dificultades, a veces impregnado de un profundo dolor, pero siempre guiado por la esperanza. Esta catástrofe que estamos padeciendo también es, paradójicamente, una experiencia en la que encontrar bendiciones, Dios ha estado cerca, nunca nos ha dejado.

\section{LA CRISIS COMO GRAN OPORTUNIDAD PARA DISCERNIR}

Las crisis ponen de manifiesto cómo somos en realidad y esa contemplación nos da claridad, sobre todo cuando es una experiencia tan súbita, profunda y breve como la que ha golpeado colectivamente nuestra salud. "Siempre la claridad viene del cielo», como dice el poeta Claudio Rodríguez. Y nos recordó Francisco en su Plan para resucitar que éste es el tiempo propicio de animarnos a una nueva imaginación de lo posible con el realismo que sólo el Evangelio nos puede proporcionar. El Espíritu, que no se deja encerrar ni instrumentalizar con esquemas, modalidades o estructuras fijas o caducas, nos propone sumarnos a su movimiento capaz de «hacer nuevas todas las cosas» (Ap 21,5).

El término «crisis» no tiene por sí mismo una connotación negativa. No se refiere solamente a un mal momento que hay que superar. La

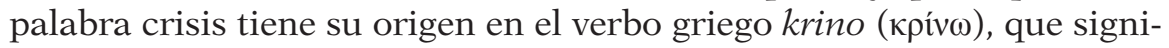
fica investigar, valorar, juzgar. Por esto, nuestro tiempo es un tiempo de discernimiento, que nos invita a valorar lo esencial y a construir sobre ello; es, por lo tanto, un tiempo de desafíos y de oportunidades ${ }^{12}$. Ya Benedicto XVI en Caritas in veritate habló de cómo «la crisis se convierte en ocasión de discernir y proyectar de un modo nuevo; conviene afrontar las dificultades del presente en esta clave, de manera confiada más que resignada» $(\mathrm{CV}, 21)$.

Amenazas y oportunidades conforman la realidad y por esto mismo es tan importante la formación en todas las dimensiones y el proceso de interiorización de nuestra responsabilidad. Como no es nada fácil mantener el rumbo hacia el bien y la verdad, aún es más importante la invitación

\footnotetext{
${ }^{12}$ Francisco. Discurso a los Jefes de Estado y de Gobierno de la Unión Europea presentes en Italia para la celebración del 60 aniversario del Tratado de Roma (24/3/2017). 
al discernimiento que pone en el centro la conciencia y el realismo de lo concreto sin perder el horizonte de los grandes ideales; discernimiento para buscar y hallar la verdad en libertad en todas las decisiones, no sólo en las fundamentales.

Discernir requiere conocer la materia, recopilar buenos datos, sopesar razones y buscar recta y humildemente lo bueno; todo para decidir. No es dar un cheque en blanco al relativismo ni al hacer la propia voluntad. Para los creyentes, supone traspasar la superficie de las cosas y las apariencias para atender amorosamente a lo que Dios espera de uno en sus circunstancias. A unos fariseos y saduceos que vinieron para tentarle y le pidieron una señal del cielo, Jesús les dijo «ihipócritas! que sabéis distinguir el aspecto del cielo, pero no distinguís las señales de la historia» (Mt 16,1-3).

\section{UN TESORO SOBRE EL DISCERNIMIENTO: EL DISCURSO DE FRANCISCO A LOS NUEVOS OBISPOS DE 2017}

El discernimiento es un remedio contra la inmovilidad del «siempre se ha hecho así» o del «tomemos tiempo». Es un proceso creativo que no se limita a aplicar esquemas. Es un antídoto contra la rigidez, porque las mismas soluciones no son válidas en todas partes. Es siempre el perenne hoy del resucitado, que nos impone la no resignación a la repetición del pasado y el valor de preguntarnos si las propuestas de ayer siguen siendo evangélicamente válidas. No nos dejemos aprisionar por la nostalgia de tener una sola respuesta para aplicar en todos los casos. Esto tal vez calmaría nuestra ansiedad de rendimiento, pero dejaría relegadas a los márgenes y «secas» vidas que necesitan ser regadas por la gracia que custodiamos (Mc 3,1-6; Ez 37,4).

El discernimiento es un don para responder a las necesidades humanas actuales, cuya posesión no se puede dar por descontada, como si se tratara de un derecho adquirido. Es necesario implorarlo constantemente como condición primaria para iluminar toda sabiduría humana, existencial, psicológica, sociológica, moral, de la que podamos servirnos en la tarea de discernir los caminos de Dios para la salvación de los que nos han sido confiados. Pablo lo presenta como uno de los dones del Espíritu (cf. 1Cor 12,10). De ahí que haya que implorarlo en la oración (cf. $1 \operatorname{Re} 3,5-12)$. 
Es un don que pide tener ante los ojos a Jesús y a la misión que no era suya sino del Padre (cf. Jn 7,16), y ofrecer a la gente - hoy como ayer confundida y perdida - todo lo que Él supo dar: la posibilidad de encontrar a Dios personalmente, de elegir su camino y de progresar en su amor.

En la Cruz está el lugar permanente del discernimiento de Dios en nuestro favor, contemplando la profundidad de su encarnación y aprendiendo de ella el criterio de todo discernimiento auténtico $(1 \mathrm{Jn} 4,1)^{13}$. La encarnación es el criterio que hemos de tener para anunciar el Evangelio (Osoro, Quiero entrar en tu casa, 54).

El discernimiento nace en el corazón y en la mente a través de la oración cuando se ponen en contacto las personas y las situaciones que nos han sido confiadas con la Palabra divina pronunciada por el Espíritu. En esa intimidad el pastor madura la libertad interior que lo hace firme en sus elecciones y comportamientos, tanto personales como eclesiales.

El discernimiento es una gracia del Espíritu al santo pueblo fiel de Dios que lo constituye Pueblo profético, dotado con ese sentido de la fe y de ese instinto espiritual que lo hace capaz de sentire cum Ecclesia. Es un don recibido en medio del Pueblo y orientado hacia su salvación.

\section{EL SENTIDO DE LA FE DEL PUEBLO}

Francisco está revalorizando o poniendo especial énfasis en la noción de sensus fidei fidelium —el sentido de la fe de todo el pueblo de Dios (LG, 12)—:

«En todos los bautizados, desde el primero hasta el último, actúa la fuerza santificadora del Espíritu que impulsa a evangelizar. El Pueblo de Dios es santo por esta unción que lo hace infalible "in credendo" [...] Como parte de su misterio de amor hacia la humanidad, Dios dota a la totalidad de los fieles de un instinto de la fe —el sensus fidei-que los ayuda a discernir lo que viene realmente de Dios. La presencia del Espíritu otorga a los cristianos una cierta connaturalidad con las realidades divinas y una sabiduría que los permite captarlas intuitivamente, aunque no tengan el instrumental adecuado para expresarlas con precisión» $(\mathrm{EG}, 119)$.

${ }^{13}$ Francisco. Discurso a los nuevos obispos ordenados durante el año 2017 (14/9/2017). 
Esta llamada al sensus fidei de todo el pueblo de Dios la hace al tiempo que activa la sinodalidad: «El camino de la sinodalidad es el camino que Dios espera de la Iglesia del tercer milenio. Lo que el Señor nos pide, en cierto sentido, ya está contenido en la palabra "Sínodo". Caminar juntos -laicos, pastores, obispo de Roma- es un concepto fácil de expresar con palabras, pero no es tan fácil ponerlo en práctica» ${ }^{14}$.

Ambos movimientos — ponerse a la escucha del sentido de la fe del pueblo y fomentar los procedimientos participativos eclesiales- responden a la lógica de abrir cauces al instinto de la fe de la totalidad del pueblo de Dios, para lo cual «los organismos permanezcan conectados con lo "bajo" y partan de la gente, de los problemas de cada día...».

En el discurso a los nuevos obispos de 2017 ya citado, dice Bergoglio: «En el diálogo sereno, el obispo no tiene miedo de compartir, e incluso a veces de modificar, su discernimiento con los demás: con los hermanos en el episcopado a los que está unido sacramentalmente, y entonces el discernimiento se vuelve colegial; con sus propios sacerdotes, de los que es garante de esa unidad que no se impone por la fuerza, sino que se teje con la paciencia y la sabiduría de un artesano; con los fieles laicos, para que conserven el «olfato» de la verdadera infalibilidad de la fe que reside en la Iglesia: saben que Dios no falla en su amor, y no desmiente sus promesas».

\section{DISCERNIR EN LA IGLESIA LOCAL}

Si en nuestra Iglesia de Madrid ya nos preguntábamos cómo ir reflexionando acerca de lo que quisiéramos para el futuro más o menos cercano, la realidad se nos impone y presiona a causa de la honda crisis de la pandemia. Se hace necesario ver qué prioridades nos reclama este momento y con qué acciones responder a las necesidades e interpelaciones de esta circunstancia y las secuelas que va a dejar inevitablemente la COVID-19 en el medio y largo plazo en el orden de la vivencia y transmisión de la

${ }^{14}$ Francisco. Discurso en la conmemoración del 50 aniversario de la institución del Sínodo de los Obispos (17/10/2015). Se pueden ver con provecho las explicaciones que proporcionan: Carlos Schikendantz. "Una recepción fiel y creativa. El Concilio Vaticano II y Francisco”. Medellín 168 (2017): 293-312, aquí 307-308; Jesús Santiago Madrigal. “La conversión pastoral del papado en una Iglesia sinodal”. Medellín 168 (2017): 313-331; Lluís Martínez Sistach. Cómo aplicar Amoris laetitia. Madrid: Ed. Claretianas, 2017. 
fe, de la familia y la vecindad, de la economía, la educación o la política, etc. Todo ello tendrá consecuencias en la forma de organizar los recursos humanos, la forma de trabajar, la necesidad de respuestas más integradas, maximizando recursos de la Iglesia local, yendo más a lo esencial y estableciendo prioridades. Transversalidad, flexibilidad, creatividad son notas de la nueva cultura organizacional. Pero ninguna de esas notas suprime que la santidad de la Iglesia local, con todo su pluralismo, brille como signo del Reino de Dios.

El Cardenal Arzobispo ha querido realizar en la diócesis, naturalmente con las debidas modulaciones y adaptaciones, este trabajo pedido por el papa, orientándolo como discernimiento comunitario y apostólico, y lo quiere llevar al modo de tratar todos los asuntos. Estamos ante algo que es más que un método, es expresión de la naturaleza de la Iglesia, que es misterio de comunión en Cristo en el Espíritu Santo. La sinodalidad no es un simple procedimiento metodológico, sino la forma histórica del caminar de la Iglesia y se alimenta en la Eucaristía (Osoro, Quiero entrar en tu casa, 11-12) y el discernimiento comunitario o formas de buscar la voluntad de Dios juntos está incardinado en ese caminar juntos.

La propuesta no trataba tanto de satisfacer el prurito de constituir un observatorio de la realidad, sino de hacer un ejercicio de leer la realidad con los ojos de la fe e ir proyectando pasos concretos y evaluables hacia un mañana que no deje a nadie en la estacada, facilite el vigor de vida de fe de las comunidades cristianas y procure la incorporación de nuevos miembros activos. El objetivo principal es proporcionar a los órganos de gobierno y de consulta elementos útiles de análisis de la realidad que permitan el discernimiento y la traducción en prioridades pastorales y propuestas operativas en todas las áreas, aportando las modulaciones precisas al Plan Pastoral de la diócesis de Madrid.

A tal fin en la archidiócesis se constituyeron cinco grupos de trabajo (ya señalados en la nota 2), cada uno encomendado a un coordinador, en todos ellos se hizo presente de algún modo el arzobispo, quien, a su vez, moduló las reuniones del cuarto y quinto grupos. Tras el trabajo de los grupos en los meses de junio y parte de julio de 2020, los coordinadores de los grupos comparecieron a final del mes de julio en el Consejo Episcopal ampliado para presentar la reflexión y propuestas de cada grupo. No han sido meros grupos de debate o de reflexión, sino de pensamiento y de invitación a la acción operativa con propuestas concretas, tratando 
siempre de sondear lo que «El Espíritu dice a la Iglesia» (Ap 2,11) y la respuesta al «¿Qué hemos de hacer hermanos?» (Hch 2,37).

\section{INSERCIÓN VS CLERICALISMO/ESPIRITUALIDAD CRISTIANA VS MUNDANIDAD}

El pueblo fiel es el que nos ubica: es la cercanía de la gente de la parroquia; al que está en un colegio, son los padres de los chicos y los mismos chicos; al que está en un hospital, son los enfermos y sus familias los que lo ubican. La «inserción» es lo opuesto al clericalismo, que es elitismo, es decir, no querer formar parte del pueblo de Dios. "De ahí pueden venir muchas consecuencias, sobre todo cuando se maneja mal el poder... Incluso detrás de los casos de abusos, además de otras inmadureces y neurosis, está el clericalismo. Hay que tener mucho cuidado con esto en la formación» ${ }^{15}$.

En la homilía de su misa de entronización dijo el papa: «El verdadero poder es el servicio, y para ejercer el poder, debe entrar cada vez más en ese servicio que tiene su culmen luminoso en la cruz; debe poner sus ojos en el servicio humilde, concreto, rico de fe, de san José y, como él, abrir los brazos y custodiar a todo el pueblo de Dios y acoger con afecto y ternura a toda la humanidad, especialmente a los más pobres, los más débiles, los más pequeños; eso que Mateo describe en el juicio final sobre la caridad» ${ }^{16}$.

A los sacerdotes, la cuestión de la inculturación de la misión y la inserción en el pueblo fiel nos lanza la pregunta de si estamos dispuestos a aceptar la realidad de nuestro mundo, con sus luces y sombras, pero no de un mundo imaginario, sino el mundo en el que vivimos, porque la llamada que hemos recibido de Jesús no es difusa e indiferenciada.

Esa llamada es a comprometernos con el mundo como es, al que Dios ama, y no a romper con él. Necesitamos una visión pascual de la historia, con apertura a un mundo que estamos convencidos se deja transformar y puede ser transformado. Ello obliga a hablar de una espiritualidad

15 Francisco. La fuerza de la vocación. La vida consagrada hoy. Madrid: Ed. Claretianas, 2018, 77-78.

${ }^{16}$ Francisco. Homilía de entronización (19/3/2013). Cf. Jorge Mario Bergoglio. El poder es el servicio. Madrid: Ed. Claretianas, 2013. 
capaz de inspirar un trabajo que no es puramente secular, ni puramente profesional, sino testimonio de la presencia de un Dios amante y salvador: la justicia que brota de la fe en Cristo tiene que estar marcada por el mandamiento nuevo del amor.

Si el clericalismo es lo opuesto a la inserción. Lo contrario a una espiritualidad auténtica es la mundanidad: «Tener los criterios del mundo en vez de los de Jesús es todo lo contrario a lo que significa la consagración religiosa»; "en vez de buscar la gloria del Señor, buscar la gloria humana», siempre - eso sí- so capa de bien ${ }^{17}$.

Concluyo con una cita que quiere recoger y canalizar lo más esencial de todas las llamadas explicitadas:

«El Evangelio tiene un criterio de totalidad que le es inherente: no termina de ser Buena Noticia hasta que no es anunciado a todos, hasta que no fecunda y sana todas las dimensiones del hombre, y hasta que no integra a todos los hombres en la mesa del Reino... La Buena Noticia es la alegría de un Padre que no quiere que se pierda ninguno de sus pequeñitos» (EG, 237).

\section{REFERENCIAS}

Archidiócesis de Madrid. Un plan para resucitar. Grupos de trabajo y reflexiones sobre la Iglesia en la pandemia. Madrid, 2020. Ad usum privatum. Benedicto XVI. Discurso a los obispos suizos (9/11/2006).

Bergoglio, Jorge Mario. El poder es el servicio. Madrid: Ed. Claretianas, 2013.

Bru, Manuel. “¿Qué significa la Cultura del Encuentro?”. Aleteia (26 de noviembre de 2014) (acceso web 18/8/2016).

Congregación para la doctrina de la fe. Carta Samaritanus bonus sobre el cuidado de las personas en las fases críticas y terminales de la vida (22/9/2020).

Francisco. Discurso a los Jefes de Estado y de Gobierno de la Unión Europea presentes en Italia para la celebración del 60 aniversario del Tratado de Roma (24/3/2017).

17 Francisco. La fuerza de la vocación, 88. 
Francisco. Discurso a los nuevos obispos ordenados durante el año 2017 (14/9/2017).

Francisco. Discurso del Santo Padre Francisco a los participantes en la $36 .^{\circ}$ Congregación General de la Compañía de Jesús (24/10/2016). Roma: Curia General de la Compañía de Jesús, 2016, n. 2.

Francisco. Discurso en la conmemoración del 50 aniversario de la institución del Sínodo de los Obispos (17/10/2015).

Francisco. Entrevista al papa Francisco del P. Antonio Spadaro, SJ. L'Osservatore Romano, edición semanal en lengua española, Año XLV, n. 39 (2.333), viernes 27 de septiembre de 2013.

Francisco. Homilía de entronización (19/3/2013).

Francisco. La fuerza de la vocación. La vida consagrada hoy. Madrid: Ed. Claretianas, 2018.

Francisco. Mensaje en la Fiesta de san Cayetano-Argentina (7/8/2013).

Francisco. "Bula Misericordiae vultus". AAS 107 (2015): 399-420.

Francisco. "Exhortación apostólica Evangelii gaudium". AAS 105 (2013): 1019-1137.

Francisco. "Encíclica Laudato si'. Sobre el cuidado de la casa común". AAS 107 (2015): 847-945 (24/5/2015).

Francisco. Encíclica Fratelli tutti. Sobre la fraternidad y la amistad social $(3 / 10 / 2020)$.

Han, Byung-Chul. La desaparición de los rituales. Barcelona: Herder, 2020.

Madrigal, Jesús Santiago. "La conversión pastoral del papado en una Iglesia sinodal". Medellín 168 (2017): 313-331.

Martínez Sistach, Lluís. Cómo aplicar Amoris laetitia. Madrid: Ed. Claretianas, 2017.

Nicolás, Adolfo. Misión y Universidad ¿Qué futuro queremos? Barcelona: ESADE, 2008.

Osoro, Carlos. Carta pastoral "Quiero entrar en tu casa". Madrid: Ed. Arzobispado de Madrid, 2020.

Schikendantz, Carlos. "Una recepción fiel y creativa. El Concilio Vaticano II y Francisco". Medellín 168 (2017): 293-312. 